\title{
Eğimli Zeminlerde İnşa Edilen Betonarme Binaların Deprem Davranışlarının İncelenmesi
}

\author{
Ercan Işı1 ${ }^{1 *}$, İbrahim Baran Karaşin², Ali Emre Ulu ${ }^{3}$ \\ 1*Bitlis Eren Üniversitesi, Müh.-Mim Fakültesi, İnşaat Mühendisliği Bölümü, Bitlis, Türkiye,(ORCID: 0000-0001-8057-065X), eisik@beu.edu.tr \\ ${ }^{2}$ Dicle Üniversitesi, Müh. Fakültesi, İnşaat Mühendisliği Bölümü, Bitlis, Türkiye, (ORCID: 0000-0001-5990-1215), barankarasin@ gmail.com \\ ${ }^{3}$ Bitlis Eren Üniversitesi, Müh.-Mim Fakültesi, İnşaat Mühendisliği Bölümü, Bitlis, Türkiye,(ORCID: 0000-0001-7499-3891), aliemreulu @ gmail.com
}

(İlk Geliş Tarihi 25 Haziran 2020 ve Kabul Tarihi 11 Ekim 2020)

(DOI: 10.31590/ejosat.757763)

ATIF/REFERENCE: Işıı, E., Karaşin, İ.B., \& Ulu, A.E. (2020). Eğimli Zeminlerde İnşa Edilen Betonarme Binaların Deprem Davranışlarının İncelenmesi. Avrupa Bilim ve Teknoloji Dergisi, (20), 162-170.

\section{$\ddot{O} z$}

Yapıların inşa edileceği zeminler eğimli olabilmektedir. Çoğu zaman tabii zemin eğimi ortadan kaldırılarak farklı kot seviyelerine oturan temeller engellenmektedir. Ancak bazı durumlarda yapı zemin eğimine göre inşa edilebilmektedir. Bu gibi durumlarda yapının zemin katında bulunan düşey taşıyıcı elemanlar farklı yüksekliklerde inşa edilebilmektedir. Bu çalışma kapsamında 3\%, $5 \%$ ve $10 \%$ zemin eğimleri dikkate alınmıştır. Elde edilen sonuçların karşılaş̧ırılabilmesi adına zemin eğimin dikkate alınmadığı referans betonarme bina için hesaplamalar yapılmıştır. Oluşturulan dört farklı yapı modeli için statik itme ve özdeğer analizleri yapılmıştır. Yapısal modellerin tamamında değişken olarak sadece zemin kat kolon yükseklikleri seçilmiştir. Yapısal analizlere esas olan diğer tüm değerler sabit olarak alınmıştır. Her bir yapısal model için periyot, yer değiştirme, taban kesme kuvvet, elastik ve efektif rijitlik ile hasar durumları için üç farklı hedef deplasman değerleri ayrı ayrı hesaplanmıştır. Her bir yapı modeli için ilk ve son hasar şekilleri elde edilmiştir. Zemin eğiminden dolayı oluşan kısa kolonlar yapının deprem performansını olumsuz olarak etkilemektedir. Zemin eğiminin artmasından dolayı zemin katta yer alan kolon yüksekliklerindeki azalma yapının rijitlik değerlerini arttırmakta, periyot değerlerini azaltıp, yapının sismik kapasitesini arttırmaktadır. Ancak zemin eğiminin fazla olduğu yapı modellerinde daha düşük yük faktörleri altında ilk hasarlar meydana gelmiştir. Oluşan ilk hasarlar eğimden dolayı en düşük yüksekliklere sahip kolonlarda oluşmuştur. Yer değiştirme istem talepleri zemin eğiminin arttığı yapı modellerinde azalmıştır.

Anahtar Kelimeler: Betonarme, Statik itme analizi, Kısa kolon, Farklı zemin eğimi

\section{Investigation of Earthquake Behavior of Reinforced-Concrete Buildings Built on Soil Slope}

\begin{abstract}
The soils on which the structures will be built can be sloping. The soil slope was mostly eliminated; therefore, different levels on foundations were prevented., the ground slope is eliminated and foundations sitting at different levels are prevented. But in some cases the structure can be built according to the soil slope. The vertical structural elements on the ground story can be built with different heights according to the soil slope. 3\%, 5\% and 10\% soil slopes were taken into account in this study. Structural analysis was performed for the reference reinforced-concrete building model without soil slope in order to compare the results. Static pushover and eigen value analyzes were carried out for four different building models. Ground story columns heights were chosen as one variable according to the soil slope in all structural models. All other values that are the basis of structural analysis are taken as constant. The periods, base shear force, elastic and effective rigidity, target displacements for three different damage status was calculated separately for all structural models. Additionally, the initial and last damage status was obtained for all structural models. . Short columns formed due to the soil slope negatively affect the earthquake behavior of the building. Due to the increase of the soil slope, the decrease in column heights on the ground story increases the stiffness values, decreases the period values and increases the seismic demands of the structural models. However, in structural models with high soil slope, initial damages occurred under lower load factors. The initial damages occurred in columns with the lowest heights due to the soil slope. The displacement demands decreased in building models, where the soil slope of the soil increased.
\end{abstract}

Keywords: Reinforced concrete, Pushover analysis, Short column, Different soil slope 


\section{Giriş}

Yıkıcı depremlerden sonra oluşan değişik çaptaki yapısal hasarlar, yapıların deprem performanslarının incelenme gereksinimini ve önemini ortaya koymaktadır. Yapıların deprem performansı, belirli bir deprem etkisi altında yapıda oluşabilecek hasarların düzey ve dağılımına bağlı olarak belirlenen yapı güvenliği durumu olarak ifade edilmektedir. Depremin büyüklüğü ve yeterli düzeyde güvenliği sağlanmamış ve yönetmeliklerde belirtilen şartlara uygun yapılmayan yapılar ile olumsuz yap1 özellikleri de oluşabilecek zararı doğrudan etkileyecektir. Özellikle yıkılma veya ağır hasar görme riski yüksek olan binaların güçlendirilmesi, eğer güçlendirme işlemi ekonomik olarak verimli değilse de yıkılarak yeniden yapılması depremde en etkili zarar azaltma önlemidir (Sucuoğlu vd., 2007; Ulutaş vd., 2019; Işık vd., 2017; Tekeli vd., 2017).

Yapıların, deprem yükleri altında davranışlarını olumsuz olarak etkileyecek birçok parametre bulunmaktadır. Kısa kolon, ağır çıkmalar, yumuşak/zayıf kat, planda düzensizlik, tepeyamaç etkisi, bölgenin depremselliği, yerel zemin koşulları, düşeyde düzensizlik, yapısal özellikler ve çarpışma etkisi gösterebilecek bitişik nizam gibi olumsuzluk parametreleri betonarme yapılar için kullanılan hızlı değerlendirme yöntemlerinde de kendine yer bulmuştur. Yapıların savunma mekanizmasını zayıflatacak bu parametreler, oluşabilecek hasarın miktarını arttıracaktır. $\mathrm{Bu}$ parametreler zorunluluk arz ediyorsa gerekli önlemler alınarak yapının savunma mekanizması güçlendirilmelidir (Yakut, 2004; Işık, 2016; Šipoš ve Hadzima-Nyarko, 2017; Işık vd., 2018; Arslan, 2010; Hadzima-Nyarko ve Šipoš, 2017; Xian vd., 2016; Arslan vd., 2008; Yakut vd., 2017). Yapıların savunma mekanizmasını zayıflatacak parametrelerden biri de tepe-yamaç etkisi veya tabii zemin eğimidir. Binanın belirgin olarak bir tepe üstünde olması veya yüksek eğimli bir yamaçta bulunması, maruz kalacağı veya kaldığı deprem etkilerini bir miktar arttıracaktır (Özcebe vd., 2003; Karaşin vd., 2017; Tezcan vd., 2011; Bal vd., 2007; Sreerama ve Ramancharla, 2013). Jeolojik ve topografik nedenlerden dolayı bazı durumlarda binanın zeminle birleştiği katta seviye farkları oluşmaktadır $\mathrm{Bu}$ da en alt katta yer alan kolon elemanları arasındaki yükseklik farklarına neden olarak kolon boylarının uzun veya kısa olması sonucunu doğurmaktadır (Şekil 1).

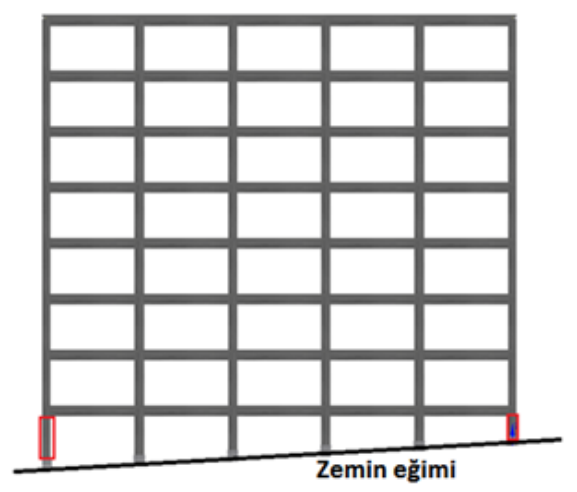

Şekil 1. Eğimli zeminde kolon boylarının farklı değerler alması

Son yüzyılda tepe alanlarının ekonomik gelişimi, yap1 tarzının yeniden düşünülmesine, inşaat malzemesinin optimum kullanımı ve inşaat yöntemine yol açmıştır. Düz arazinin tepelerdeki kıtlığı nedeniyle, dik yamaçlarla inşa edilmiş evler, özel yapısal ve yapım problemleri ortaya çıkarmaktadır. Tepe eğimlerinde inşa edilen betonarme çerçeveli yapılar, düz zemin üzerinde olduğundan farklı yapısal davranış göstermektedir (Mohammad vd., 2017; Ghosh ve Debbarma, 2017; Shakib ve Pirizadeh, 2013; Khadiranaikar ve Masali, 2014).

$\mathrm{Bu}$ çalışma, farklı zemin eğimlerinden dolayı zemin katta yer alan kolon yüksekliklerinin değiştiği kabul edilerek, tepeyamaç etkisinde yapının maruz kalacağı herhangi bir depremde göstereceği davranışı belirlemek adına yapılmıştır. Hiç eğim içermeyen tamamen düzgün ve düz zemine inşa edilen 8 katlı betonarme bina referans olarak seçilmiştir. Zemin eğiminin yap1 deprem davranışına etkisini belirlemek adına, 3\%, 5\% ve $10 \%$ olmak üzere üç farklı zemin eğimi dikkate alınmıştır. Zemin eğiminden dolayı zemin katta yer alan kolonların yükseklikleri zemin eğimine göre değişken alınarak üç farklı yapı modeli ayrıca oluşturulmuştur. Oluşturulan dört farklı yapı modeli için özdeğer ve statik itme analizleri yapının her iki doğrultusu için ayrı ayrı gerçekleştirilmiştir. Her bir yapı modeli için periyot, yer değiştirme, taban kesme kuvvet, elastik ve efektif rijitlik ile hasar durumları için üç farklı hedef deplasman değerleri ayrı ayrı hesaplanmıştır. Her bir yapı modeli için ilk ve son hasar şekilleri elde edilmiştir. Çalışma ile zemin eğiminden dolayı kolon yükseklik değişiminin zorunlu olması durumunda yapıların deprem performansları belirlenmeye çalışılmıştır. Çalışma ile ayrıca tabii zemin eğiminden dolayı zemin katta oluşacak kısa kolonların deprem etkisindeki davranışlarının belirlenmesi amaçlanmıştır.

\section{Materyal ve Metot}

\section{1. Çalışmada Kullanılan Analizler}

Çalışma kapsamında iki farklı analiz türü dikkate alınmıştır. İlk olarak her bir yapısal model için özdeğer analizi yapılmıştır. Yapılar deprem etkisinde rastgele titreşirler. $\mathrm{Bu}$ titreşim, aslında harmonik olan modların birleşimidir. $\mathrm{Bu}$ modların analizi için bir özdeğer analizi gerekli olmaktadır. Herhangi bir yapı için mod şekilleri ve doğal frekans, özdeğer analizi ile elde edilebilir. Kısaca, saf bir elastik yapısal analiz olarak düşünülebilir. Özdeğer analizi yapı ile ilgili periyot, frekans, katılım modal faktörleri, etkili modal kütleler ve bunların yüzde değerleri elde edilebilmektedir (Antoniou and Pinho, 2003; Ordu ve Özkan, 2006; Kutanis vd., 2017; Nikoo vd., 2017; Aksoylu ve Arslan, 2017).

Çalışmada ayrıca her bir yapı modeli için statik itme analizi gerçekleştirilmiştir. $\mathrm{Bu}$ analiz türü olası bir deprem etkisinde yapıların deprem davranışlarını hesaplamakta yaygın olarak kullanılmaktadır. Taşıyıcı sistem elemanlarında oluşabilecek hasar seviyeleri belirlenebilmektedir. Oluşan hasarların kabul edilebilir hasar limitleri altında kalıp kalmadığı kontrol edilebileceği gibi hasar limitleri çeşitli deprem düzeylerinde yapı için öngörülen performans hedefleri ile uyumlu olacak şekilde tanımlanabilir. Statik itme analizi ile koordinatları "tepe yer değiştirmesi - taban kesme kuvveti" olan itme eğrisi elde edilmektedir. Statik itme eğrisi, bir yapının sıfır konumundan kararsız hale gelinceye kadar geçen süre içerisinde yapıya arttırılarak uygulanan yük etkisi altında taban kesme kuvvetlerine karşılık gelen çatı deplasman değerlerinin bir etkileşim diyagramı üzerinde kesişen noktaların geometrik olarak birleştirilmesi ile elde edilen diyagramdır (Chopra ve Goel, 2002; Hsiao vd., 2015; Estêvão ve Oliveira, 2015; Ademovic vd., 2013; Ademović ve Hrasnica, 2015; Işık ve 
Kutanis, 2015). Tipik bir statik itme eğrisi Şekil 2'de gösterilmiştir.

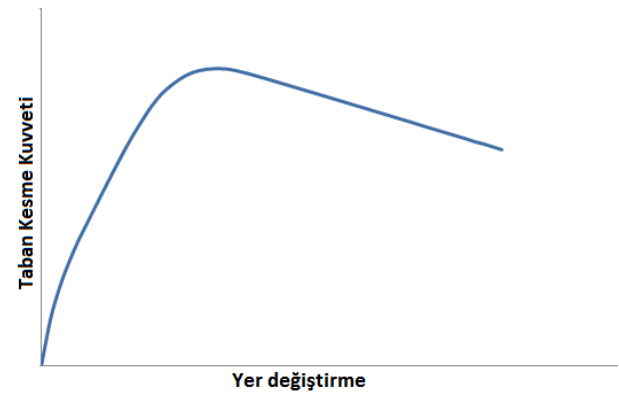

Şekil 2. Tipik statik itme ĕgrisi

\section{1. İncelenen Yapı Modellerinin Özellikleri}

Çalışma kapsamında aynı yapısal özelliklere sahip sekiz katlı betonarme bir bina örnek olarak seçilmiştir. Analizler hem $\mathrm{X}$ hem de $\mathrm{Y}$ doğrultusunda gerçekleştirilmiştir. Analizler akademik lisanlı olarak Seismostruct yazılımı ile (Seismosoft, 2013) gerçekleştirilmiştir. Yapı hem X hem Y doğrultularında beşer açıklıktan oluşmakta ve her bir açıklık $5 \mathrm{~m}$ olarak seçilmiştir. Seçilen referans binada herhangi bir düzensizlik bulunmaktadır. Örnek olarak seçilen betonarme yapıda yap1 önem sınıfı olarak II. sınıf ve sönüm oranı olarak \%5 değeri dikkate alınmıştır. Temel zemin sınıfi için kullanılan yazılımda yer alan ZA seçimi yapılmıştır. Malzeme modelleri deprem ile ilgili analizlerde önemli bir yere sahiptir (Işık ve Özdemir, 2017; Işık vd., 2019) . Örnek olarak seçilen betonarme bina için beton malzeme modeli olarak Mander vd. (1988) tarafindan önerilen doğrusal olmayan beton modeli kullanılırken, çelik içinse Menegetto-Pinto (1973) tarafindan önerilen çelik malzeme modeli dikkate alınmıştır. Dikkate alınan betonarme yapıya ait kat kalıp planı Şekil 3'te verilmiştir.

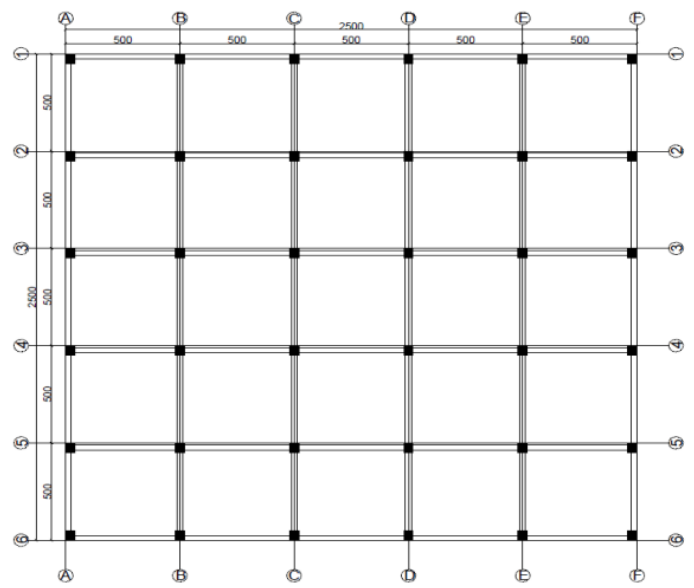

Şekil 3. Örnek olarak seçilen betonarme yapıya ait kat kalıp planı

Çalışmada kullanılan betonarme yapı için yazılım programından elde edilen iki ve üç boyutlu yapı modelleri ve uygulanan yüklerin gösterimi Şekil 4 'te verilmiştir. Yükler için üniform dağılım seçeneği kullanılmıştır.
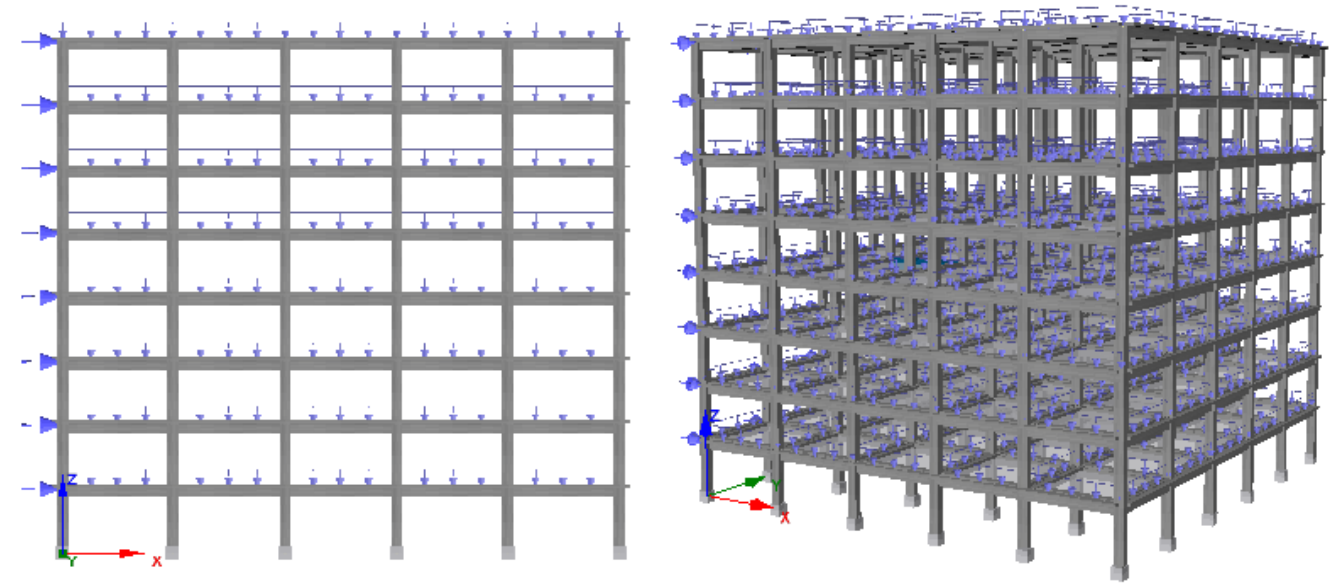

Şekil 4. Çalışmada dikkate alınan betonarme yapının 2 ve 3 boyutlu modelleri ve uygulanan yükler

Çalışmada dikkate alınan betonarme yapı modellerin tamamında malzeme olarak C25-S420 dikkate alınmıştır. Betonarme binada kullanılan kolon ve kiriş en kesitleri Şekil 5 'te verilmiştir. Hem kolon hem de kirişlerde enine donatı olarak $\phi 10 / 10$ seçilmiştir. Kolonlarda boyuna donatı olarak köşelerde $4 \phi 20$, diğer boyuna donatılar ise $8 \phi 16$ olarak seçilmiştir. Kirişlerde ise alt ve üst bölgede $4 \phi 14$ ve gövde donatısı olarak de $2 \phi 12$ seçimi yapıllmıştır.
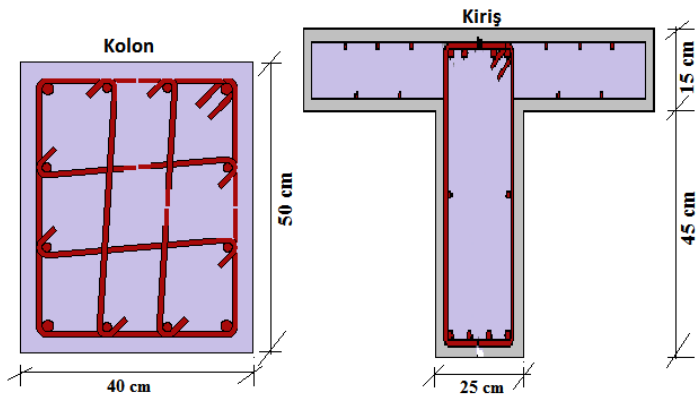

Şekil 5. Çalışmada kullanılan kolon ve kirişlere ait enkesitler 
Tüm yapısal modeller oluşturulurken kolon ve kirişler için kuvvete dayalı plastik mafsal çerçeve elemanları (infrmFBPH) kullanılmıştır. $\mathrm{Bu}$ elemanlar yayılı inelastisiteyi kuvvete dayalı olarak modeller ve yalnızca plastisiteyi sonlu bir uzunlukla sınırlandırır. Kesitte bulunan ideal fiber (lif) sayısı kesitteki gerilme- birim şekil değiştirme dağılımın modellemeye yetecek kadar olmalıdır (Antoniou ve Pinho, 2003). Seçilen yapısal kesitler için 100 (yüz) adet fiber (lif) elemanı tanımlanmıştır. Bu değer bu tür kesitler için yeterli olmaktadır.

Kat yüksekliği değeri tüm katlarda $3 \mathrm{~m}$ olarak seçilmiştir. Ancak zemin eğiminden dolayı dikkate alınan yapısal modellerde zemin kat yüksekliği farklılık göstermektedir. Tüm yapısal özellikler sabit tutularak sadece zemin eğiminden dolayı yapının zemin katında yer alan kolon boyları değişken olarak seçilmiştir. Çalışma kapsamında zemin eğiminin hiç olmadığ durum referans bina olarak ifade edilmiştir. Eğim değişken olarak seçilmiştir. $\% 3, \% 5$ ve $\% 10$ olmak üzere üç farklı eğim seçilerek yapı modellemesi yapılmıştır. Yap1 modellerinde dikkate alınan eğimler Tablo 1'de gösterilmiştir. Analizler yerdeğiştirme kontrollü olarak yapılmış ve hedef deplasman değeri tüm yapısal modellerde eşit olmak üzere $0.48 \mathrm{~m}$ olarak seçilmiştir. Analizler üç boyutlu modeller dikkate alınarak yapılmıştır.

Tablo 1. Dikkate alınan yapı modelleri ve kolon yükseklikleri

\begin{tabular}{c|c|c|c|c|c|c|c}
\hline \multirow{2}{*}{ Model No } & \multirow{2}{*}{ Ĕgim (\%) } & \multicolumn{5}{|c}{ Zemin Kat Kolon Yükseklikleri (m) } \\
\cline { 3 - 9 } & & A-A & B-B & C-C & D-D & E-E & F-F \\
\hline Model 1 & 0 & 3.00 & 3.00 & 3.00 & 3.00 & 3.00 & 3.00 \\
\hline Model 2 & 3 & 2.25 & 2.40 & 2.55 & 2.70 & 2.85 & 3.00 \\
\hline Model 3 & 5 & 1.75 & 2.00 & 2.25 & 2.50 & 2.75 & 3.00 \\
\hline Model 4 & 10 & 0.50 & 1.00 & 1.50 & 2.00 & 2.50 & 3.00 \\
\hline
\end{tabular}

Dikkate alınan yapısal modellerde kolon yükseklik farklarının daha net bir biçimde ortaya konması adına kullanılan

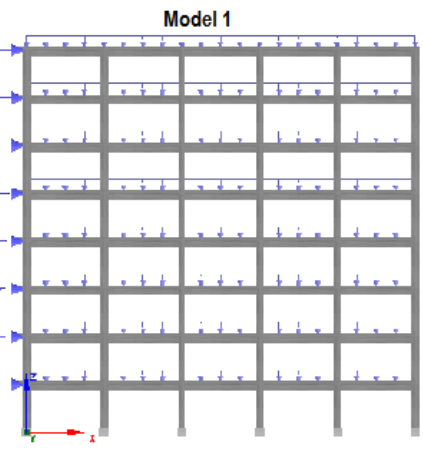

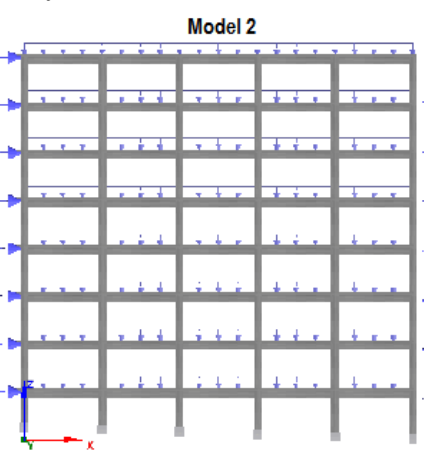

yap1 modellerine ait iki boyutlu modeller Şekil 6'da gösterilmiştir.
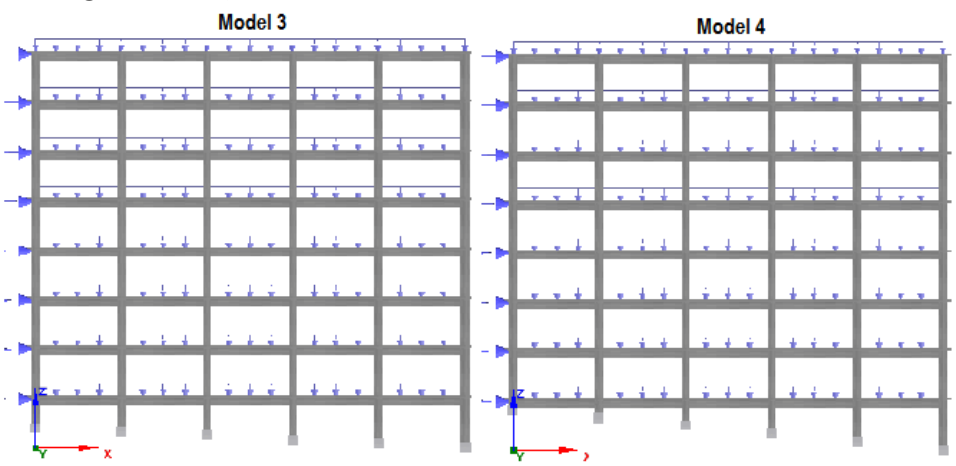

Şekil 6. Çalışmada dikkate alınan yapı modellerine ait 2 boyutlu modeller

Farklı eğimlerden dolayı yapının zemin katında yer alan kolon yüksekliklerinin değişimi dikkate alınarak elde edilen üç boyutlu yapı modelleri Şekil 7'de verilmiştir.
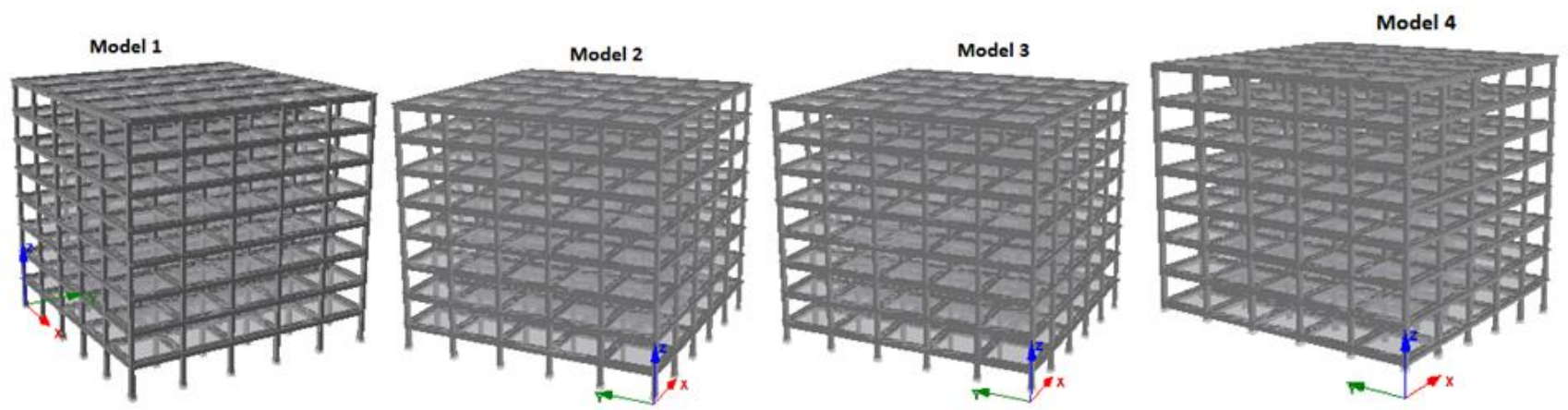

Şekil 7. Çalışmada dikkate alınan yapı modellerine ait 3 boyutlu modeller 


\section{Araştırma Sonuçları ve Tartışma}

Her bir yapı modeli için özdeğer ve statik itme analizleri ayrı ayrı yapılmıştır. Sekiz katlı olarak seçilen betonarme yapı için özdeğer analiz sonuçlarından elde edilen periyot ve frekans değerlerinin karşılaştırılması Tablo 2‘de verilmiştir.

Tablo 2. Farklı ĕgimlere sahip yapılar için elde edilen periyot ve frekans değerleri

\begin{tabular}{c|c|c|c|c|c|c|c|c}
\hline \multirow{2}{*}{ Mod } & \multicolumn{4}{|c|}{ Periyod (saniye) } & \multicolumn{4}{c}{ Frekans (Hertz) } \\
\cline { 2 - 8 } & Model 1 & Model 2 & Model 3 & Model 4 & Model 1 & Model 2 & Model 3 & Model 4 \\
\hline 1 & 0.630959 & 0.611646 & 0.59982 & 0.568812 & 1.58489 & 1.634933 & 1.667166 & 11.04615 \\
\hline 2 & 0.551853 & 0.535053 & 0.523816 & 0.496968 & 1.812076 & 1.868973 & 1.909067 & 12.64303 \\
\hline 3 & 0.551509 & 0.533983 & 0.522651 & 0.496814 & 1.813208 & 1.872718 & 1.913324 & 12.64695 \\
\hline 4 & 0.209328 & 0.202691 & 0.198609 & 0.188143 & 4.777184 & 4.933618 & 5.035016 & 33.39586 \\
\hline 5 & 0.182575 & 0.17664 & 0.172788 & 0.164105 & 5.477203 & 5.66123 & 5.787431 & 38.28763 \\
\hline 6 & 0.181897 & 0.176091 & 0.17219 & 0.163089 & 5.497615 & 5.678882 & 5.807543 & 38.526 \\
\hline 7 & 0.123791 & 0.119872 & 0.117396 & 0.111297 & 8.078137 & 8.3422 & 8.51816 & 56.45402 \\
\hline 8 & 0.107992 & 0.104455 & 0.102133 & 0.096935 & 9.259957 & 9.573521 & 9.791195 & 64.81867 \\
\hline 9 & 0.106159 & 0.102735 & 0.100377 & 0.09507 & 9.419802 & 9.733755 & 9.962409 & 66.08984 \\
\hline 10 & 0.088231 & 0.085419 & 0.083553 & 0.07935 & 11.33392 & 11.70698 & 11.9685 & 79.18271 \\
\hline
\end{tabular}

Özdeğer analizleri yardımı ile elde edilen kümülatif kütle yüzde oranları Tablo 3'te verilmiştir.

Tablo 3. 8 katlı yapı için elde edilen kümülatif kütle katılım oranları (\%)

\begin{tabular}{cc|c|c|c|c|c|cc}
\hline & \multicolumn{7}{c}{ Kümülatif Kütle Katılım Oranları (\%) } \\
\cline { 2 - 9 } Mod & \multicolumn{9}{c}{$\mathrm{U}_{\mathrm{x}}$} & \multicolumn{4}{c}{$\mathrm{U}_{\mathrm{y}}$} \\
\cline { 2 - 10 } & Model 1 & Model 2 & Model 3 & Model 4 & Model 1 & Model 2 & Model 3 & Model 4 \\
\hline 1 & 0.00 & 0.00 & 0.00 & 0.00 & 83.41 & 80.72 & 78.87 & 75.43 \\
\hline 2 & 82.72 & 80.59 & 79.02 & 74.90 & 83.41 & 80.72 & 78.87 & 75.43 \\
\hline 3 & 82.72 & 80.59 & 79.02 & 74.90 & 83.41 & 81.21 & 79.71 & 75.61 \\
\hline 4 & 82.72 & 80.59 & 79.02 & 74.90 & 93.23 & 90.98 & 89.28 & 84.40 \\
\hline 5 & 82.72 & 80.59 & 79.02 & 74.90 & 93.23 & 91.03 & 89.35 & 84.41 \\
\hline 6 & 92.70 & 90.55 & 88.79 & 83.78 & 93.23 & 91.03 & 89.35 & 84.41 \\
\hline 7 & 92.70 & 90.55 & 88.79 & 83.78 & 96.62 & 94.64 & 92.92 & 87.41 \\
\hline 8 & 92.70 & 90.55 & 88.79 & 83.78 & 96.62 & 94.65 & 92.93 & 87.41 \\
\hline 9 & 96.22 & 94.26 & 92.45 & 86.81 & 96.62 & 94.65 & 92.93 & 87.41 \\
\hline 10 & 96.22 & 94.26 & 92.45 & 86.81 & 98.30 & 96.65 & 94.93 & 88.85 \\
\hline
\end{tabular}

Betonarme taşıyıcı elamanların rijitlik değerleri, deprem etkisi altında öngörülen rijitlik değerlerinde farklı olmaktadır. Bundan dolayı bu taşıyıcı elemanların tasarım ve analizlerinde etkin kesitlik rijitlik değerleri kullanılmaktadır. Deprem yükleri altında betonarme taşıyıcı sistemlerin performansının belirlenmesi için çatlamış kesitlere ait rijitlikler dikkate alınmaktadır. Çatlamış kesitlere ait etkin kesin rijitlikleri, elastik rijitlik değerinin öngörülen rijitlik azaltma katsayılarının kullanılması ile elde edilmektedir (Çağlar vd., 2015; Öztürk vd., 2017). Bu çalışma kapsamında her bir yapısal model için elastik rijitlik değeri (K_elas) ve etkili rijtlik (K_eff) değerleri program yardımı ile öngörülen rijitlik azaltma katsayılarının kullanımı ile edilmiştir. Çalışma kapsamında her bir yapı modeli için statik e-ISSN:2148-2683 itme analizi ile taban kesme kuvvetleri, akma anındaki yer değiştirme $\left(d_{y}\right)$ hesaplanmıştır. Yapıda oluşacak hasar durumları için hedef deplasmanlar değerleri de her bir yapısal model için ayrı ayrı hesaplanmıştır. Performansa dayalı deprem mühendisliğinde, yap1 elemanlarının belirli performans limitlerine ulaşıldığı anların belirlenmesi önem arz etmektedir. $\mathrm{Bu}$ bakımdan her bir yapısal model için yazılım içerisinde yer alan Eurocode 8 (Part-3) (Pinto, 2005), kriterleri dikkate alınmıştır. Buna göre, hasar durumları için üç farklı durum belirtilmiştir. Bunlar; göçme öncesi (NC), önemli hasar (SD) ve hasar sınırlaması (DL) olarak dikkate alınmıştır. Hem X hem de Y doğrultusunda analizler yapılmıştır. Yapısal hesaplamalar 
sonucu X doğrultusunda elde edilen tüm değerlerin karşılaştırılması Tablo 4’te gösterilmiştir.

Tablo 4. Farklı yapı modelleri için X doğrultusunda elde edilen sonuç değerleri

\begin{tabular}{c|c|c|c|c|c|c|c}
\hline Model & $\begin{array}{c}\text { Taban Kesme } \\
\text { Kuvveti (kN) }\end{array}$ & K_elas & K-eff & dy & DL & SD & NC \\
\hline 1 & 9982.91 & 164046.50 & 87039.83 & 0.1147 & 0.045547 & 0.058429 & 0.101295 \\
\hline 2 & 10978.76 & 173541.80 & 88792.65 & 0.1236 & 0.044498 & 0.057084 & 0.098963 \\
\hline 3 & 11079.81 & 178530.80 & 93380.89 & 0.1187 & 0.042938 & 0.055082 & 0.095493 \\
\hline 4 & 11110.58 & 198288.00 & 103848.40 & 0.1070 & 0.039519 & 0.050696 & 0.087889 \\
\hline
\end{tabular}

Yapısal hesaplamalar sonucu Y doğrultusunda elde edilen tüm değerlerin karşılaştırılması Tablo 5 'te gösterilmiştir.

Tablo 5. Farklı yapı modelleri için Y doğrultusunda elde edilen sonuç değerleri

\begin{tabular}{c|c|c|c|c|c|c|c}
\hline Model & $\begin{array}{c}\text { Taban Kesme } \\
\text { Kuvveti (kN) }\end{array}$ & K_elas & K-eff & dy & DL & SD & NC \\
\hline 1 & 7536.03 & 136616.27 & 68972.00 & 0.1728 & 0.0515933 & 0.0661856 & 0.1147424 \\
\hline 2 & 8307.00 & 145322.38 & 71166.94 & 0.1890 & 0.0513108 & 0.0658232 & 0.1141141 \\
\hline 3 & 8316.94 & 152248.59 & 74644.53 & 0.1784 & 0.0502895 & 0.064513 & 0.1118428 \\
\hline 4 & 8334.54 & 166946.58 & 83089.56 & 0.1605 & 0.0454149 & 0.0582598 & 0.1010018 \\
\hline
\end{tabular}

$X$ doğrultusunda elde edilen statik itme eğrilerinin karşılaştırılması Şekil 8'de, Y doğrultusu da Şekil 9'da gösterilmiştir.

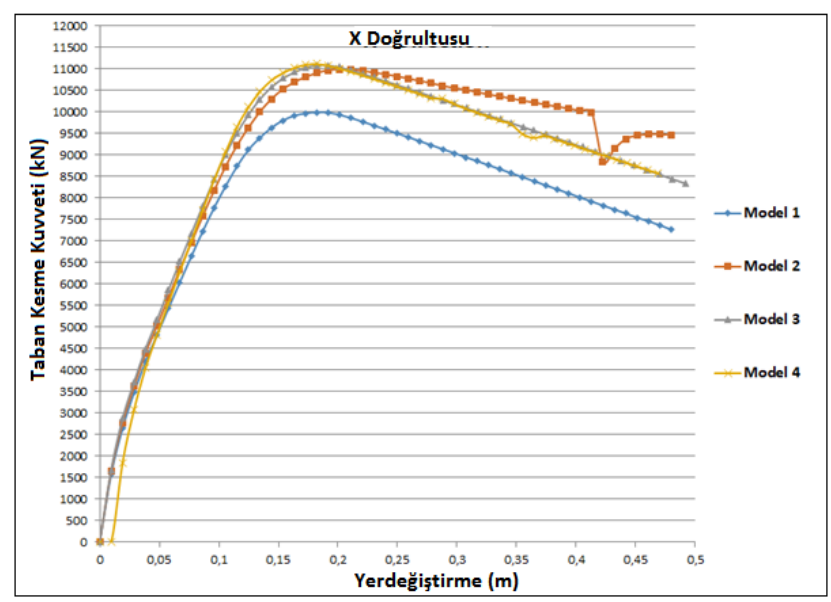

Şekil 8. X doğrultusunda elde edilen statik itme ĕgrilerin karşılaştırılması

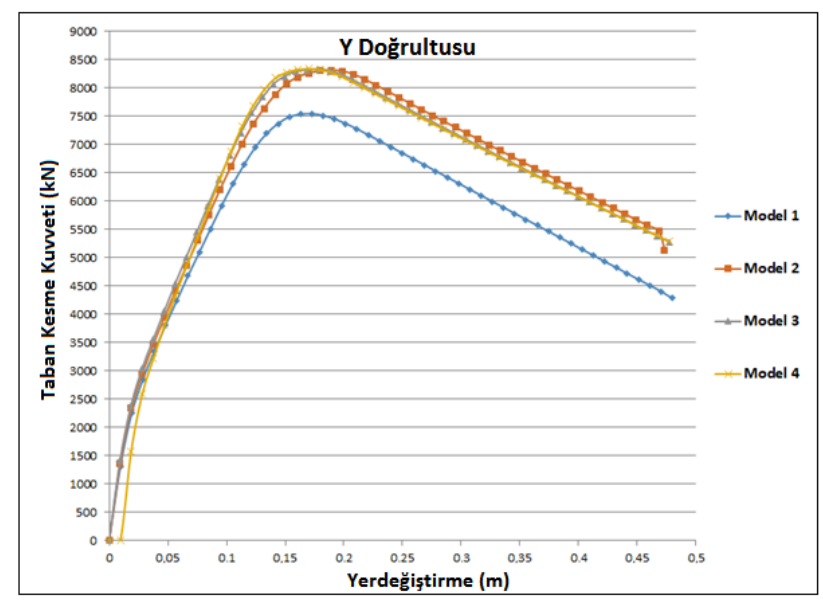

Şekil 9. Y doğrultusunda elde edilen statik itme ĕgrilerin karşılaştırılması

Yazılım programında bulunan ve ilk hasarların oluştuğu yük faktörlerinin karşılaştırılması Tablo 6‘da verilmiştir.

Tablo 6. Yük faktörlernin karşılaştırması

\begin{tabular}{c|c|c|c|c}
\hline \multirow{2}{*}{ Model } & \multicolumn{2}{|c|}{ X Dŏgrultusu } & \multicolumn{2}{c}{ Y Dŏgrultusu } \\
\cline { 2 - 4 } & Adım & Yük Faktörü & Adım & Yük Faktörü \\
\hline 1 & 10 & 72.1926 & 11 & 59.1788 \\
\hline 2 & 8 & 63.3075 & 10 & 57.4795 \\
\hline 3 & 7 & 58.5700 & 9 & 54.5515 \\
\hline 4 & 4 & 40.3922 & 5 & 38.0636 \\
\hline
\end{tabular}


Her bir yapı modelinde ilk hasarların oluştuğu kolonlar Şekil 10'de gösterilmiştir.
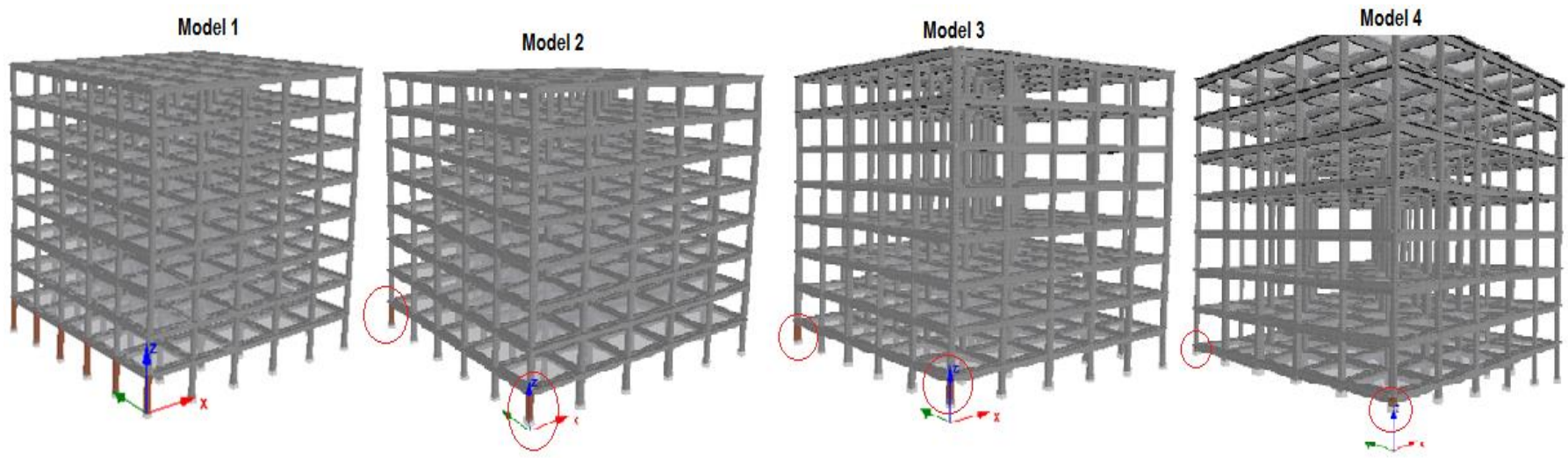

Şekil 10. Yapı modellerinde oluşan ilk hasarlar

Yapı modelleri için elde edilen son hasarların karşılaştırılması Şekil 11'de verilmiştir.
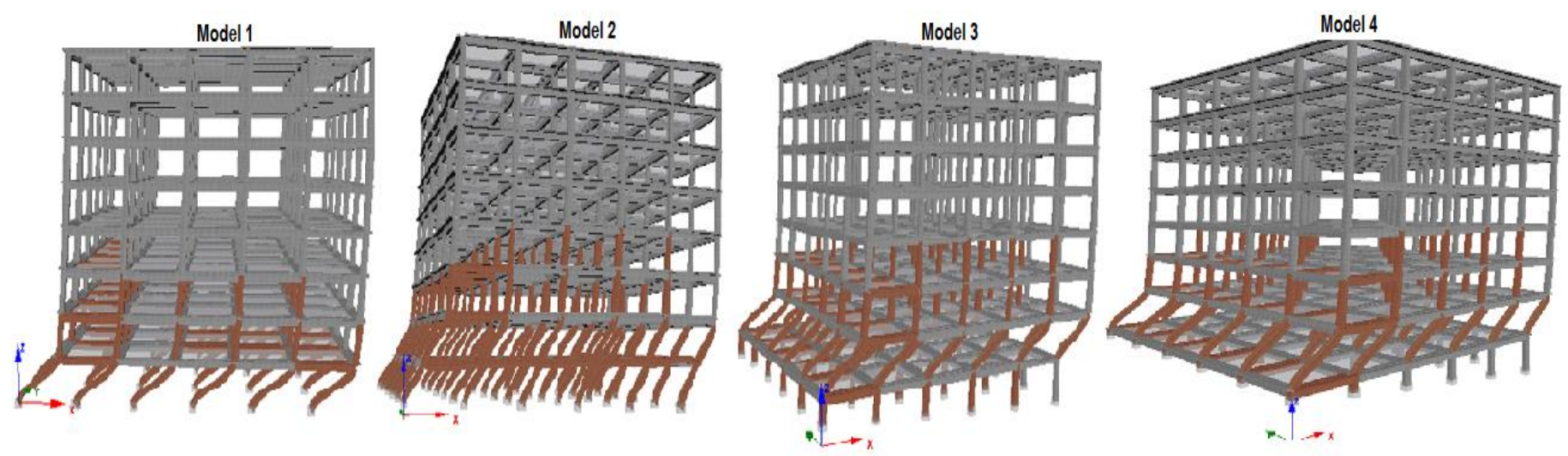

Şekil 11. Yapı modellerinde oluşan son hasarlar

Model 1'de hasarlar yatay yükün doğrudan etkilediği aks üzerinde bulunan en alttaki kolonların tamamında aynı anda başlamıştır. Bu katta bulunan kolonlar ile devam etmektedir. Bu katta bulunan tüm kolonlar hasarlar başladıktan sonra yatay yükün doğrudan etki ettiği kolonlara bağlı kirişlerde hasarlar oluşmaya başlamıştır. Model 2'de ilk hasarlar yatay yükün doğrudan etkilediği aks üzerinde kalan köşe kolonlarda başlamıştır. Daha sonra bu aks üzerinde yer alan kolonlar ile devam etmiştir. Zemin kat kolonlarının tamamında hasar oluşmadan en kısa yüksekliğe sahip kolonlara bağlı kirişler ve 1 . kattaki kolonlar ile devam etmiştir. Zemin kattaki tüm kolonlar hasar görmektedir. Model 3'te ilk hasarlar Model 2 ile aynı kolonlarda başlamıştır. Bu aksta bulunan zemin kattaki tüm kolonlar hasar aldıktan sonra yapının 1. katında yükün uygulandığ1 karşı cephedeki kolonlarda hasar oluşmaya başlamıştır. Hasar özellikle eğimden dolayı oluşan en kısa kolon yüksekliğine sahip kolon ve kirişlerde artarak devam etmiştir. Zemin katta yer alan kolonların tamamında hasar oluşmamıştır. Model 4'te ilk hasarlar aynen Model 2 ile Model 3 'tekine benzer en kısa kolon yüksekliğine sahip iki köşe kolonda oluşmuştur. Kolon yüksekliğinin en az olduğu aksta yer alan tüm kolonlar hasar gördükten sonra karşı cephedeki 1. kattaki kolonlarda hasarlar devam etmiştir. Zemin katta bulunan tüm kolonlar hasar almamıştır.
Eğim artış gösterirken kütle katılım oranları hem $\mathrm{X}$ hem de Y doğrultusunda azalış göstermiştir. Kolon yükseklik değerleri eğim arttıkça azalmakta ve yapıya ait etkin ve efektif rijitlik değerleri artış göstermiştir. Eğim arttıkça, yapıya ait rijitlik değerleri artış gösterdiğinden periyot değerleri de azalış göstermiştir. Daha rijit yapıların periyot değerlerinin daha küçük değerleri alacağı aşikardır. Bu değerlere bağlı olarak yapının taban kesme kuvvet kapasitesi de artış göstermiştir. Ancak eğim değerleri fazlalaştıkça hasar durumları için öngörülen hedef deplasman değerleri azalış göstermiştir. Eğim azalması durumunda hedef deplasman değerleri daha büyük değerler almıştır. Yük faktörü ve adım sayıları eğim arttıkça her iki doğrultuda da azalma göstermiştir. Her ne kadar periyot, rijitlik ve taban kesme kuvvet kapasiteleri her iki doğrultuda da artış göstermiş ise de yapının hasar durumları eğimin artması ile yapının savunma mekanizmasının zayıfladığını göstermiştir. Bu durum yük adımlarında kendini net bir şekilde göstermiştir. Eğim arttıkça yapıda oluşan ilk hasarlar daha erken yük adımlarında oluşmuştur.

\section{Sonuç}

Ortaya çıkabilecek zorunlu sebeplerden dolayı tabii zemin eğiminden dolayı özellikle zemin kattaki kolonlarda kot farkları 
oluşabilmektedir. Bu çalışma kapsamında farklı tabii zemin eğimlerinde inşa edilecek olan ve zemin kattaki kolonlarda kot farkının yapı deprem davranışına etkisi ortaya konmaya çalışılmıştır. Eğim artışının yapı deprem davranış analiz sonuç değerlerini ve öngörülen hasar durumları nasıl ve hangi düzeyde etkilediği belirlenmesi amaçlanmıştır. $\mathrm{Bu}$ amaç doğrultusunda eğimin hiç ve eğimin 3\%, 5\% ile 10\% olması durumlarında dört farklı sekiz katlı bir betonarme yapı seçilmiştir. Tüm yapısal özellikler sabit tutularak sadece zemin kat kolon yükseklikleri eğime bağlı olarak değiştirilmiştir. Her bir model için özdeğer ve statik itme analizleri hem $\mathrm{X}$ hem de $\mathrm{Y}$ doğrultusunda gerçekleştirilmiştir. Elde edilen tüm sonuç değerleri karşılaştırılmıştır. Yap1 modellerine ait ilk ve son hasar durumları da ayrıca elde edilmiştir.

Zemin katta yer alan kolonların zemin eğiminden dolayı daha kısa yüksekliklere sahip olması rijitlik değerlerinin artmasına sebep olmuştur. Bunun sonucu olarak Tablo 2'de belirtildiği gibi periyot değerleri daha küçük değerler almıştır. Bu bağlamda yapısal modeller için elde edilen değerler tam bir uyum göstermiştir. Zemin kat kolon yüksekliklerinin azalması ile yapıların sismik kapasiteleri artış göstermiştir. Ancak hasar durumları incelendiğinde daha düşük yük faktörleri altında yükseklik değeri düşük olan kolonlarda ilk hasarlar meydana gelmiştir. Bu da eğim miktarının artmasının yapının deprem davranışını azatlığını göstermektedir. Bu durum elde edilen performans limitlerine ulaşılma yerdeğiştirme değerlerinden gözlemlenmektedir. Daha yüksek zemin eğiminden dolay1 yükseklik değerleri azalan kolanlarda daha düşük yer değiştirme değerlerinde belirlenen performans limitlerine ulaşılmıştır.

Elde edilen tüm analiz sonuçları birlikte değerlendirildiğinde zemin eğiminin artması ile kolon yükseklik değerlerinin azalması yapının savunma mekanizmasını olumsuz olarak etkilemektedir. Özellikle kolon yüksekliklerinin azalması eğim etkisinin yanı sıra kısa kolon kavramını da ortaya çıkarmıştır. Olumsuz jeolojik ve topografik faktörler nedeniyle farklı seviyelerde inşa edilen yapılarda kısa kolon oluşumları meydana gelecektir. Dolaysıyla yapıya ait sadece tepe-yamaç etkisi olumsuzluk parametresinin yanı sira k1sa kolon olumsuzluk parametresi de eklenmiştir. $\mathrm{Bu}$ bağlamda yapı savunma mekanizmasının deprem yükleri altında zayıflatabilecek bu ve benzeri uygulamalardan mümkün olduğu kadar kaçınılmalıdır. Özellikle eğim etkisi yapılacak kazı işlemleri ortadan kaldırılabilecektir. Eğer bu durum ortadan kaldırılamıyor ise gerekli önlemler alınmalıdır. Hiç eğim olmayan referans bina için elde edilen periyot değerlerinin eğimli zeminlerde inşa edilecek yapı model periyot değerlerinden büyük çıkması referans binaya hareket kabiliyeti sağlayarak sönüm miktarını arttıracaktır. Ayrıca tepe-yamaç etkisi veya eğimli zeminlerde inşa edilecek binalar için heyelan, kaya düşmesi ve çığ gibi doğal afetlerin etkisinin de olabileceği unutulmamalıdır. $\mathrm{Bu}$ afetler ile birlikte deprem etkisi dikkate alındığında ortaya çıkabilecek çoklu afet etkisi için özel önlemler alınmalıdır.

\section{Kaynakça}

Ademovic, N., Hrasnica, M., \& Oliveira, D.V. (2013). Pushover analysis and failure pattern of a typical masonry residential building in Bosnia and Herzegovina. Engineering $\begin{array}{lrr}\text { Structures, } & 50, & 13-\end{array}$ https://doi.org/10.1016/j.engstruct.2012.11.031

Ademović, N., \& Hrasnica, M. (2015). Capacity degradation and crack pattern development in a multi-storey unreinforced e-ISSN:2148-2683 masonry building. Građevinar, 67(04), 351-361. https://doi.org/10.14256/JCE.1191.2014

Antoniou, S., \& Pinho, R. (2003). Seismostruct - Seismic Analysis program by Seismosoft. Technical manual and user manual.

Aksoylu, C., \& Arslan, M. H. (2019). Çerçeve+perde türü betonarme binaların periyod hesaplarının TBDY-2019 yönetmeliğine göre ampirik olarak değerlendirilmesi. Uludağ University Journal of The Faculty of Engineering, 24(3), 365-382. https://doi.org/10.17482/uumfd.603437

Arslan, M. H. (2010). An evaluation of effective design parameters on earthquake performance of RC buildings using neural networks. Engineering Structures, 32(7), 1888-1898. https://doi.org/10.1016/j.engstruct.2010.03.010

Arslan, M. H., Köroğlu, M. A., \& Köken, A. (2008). Binaların yapısal performansının statik itme analizi ile belirlenmesi. Yapı Teknolojileri Elektronik Dergisi, 4(2), 71-84.

Bal, İ.E., Tezcan, S. S., \& Gülay, F.G. (2007). Betonarme binaların göçme riskinin belirlenmesi için P25 hızlı değerlendirme yöntemi. Altıncı Ulusal Deprem Mühendisliği Konferans1, 16-20 Ekim 2007, İstanbul.

Chopra, A. K., \& Goel, R. K. (2002). A modal pushover analysis procedure for estimating seismic demands for buildings. Earthquake Engineering \& Structural Dynamics, 31(3), 561-582. https://doi.org/10.1002/eqe.144

Caglar, N., Demir, A., Ozturk, H., \& Akkaya, A. (2015). A simple formulation for effective flexural stiffness of circular reinforced concrete columns. Engineering Applications of Artificial Intelligence, 38, 79-87. https://doi.org/10.1016/j.engappai.2014.10.011

Estêvão, J. M., \& Oliveira, C. S. (2015). A new analysis method for structural failure evaluation. Engineering Failure Analysis, 56, https://doi.org/10.1016/j.engfailanal.2014.08.009

Ghosh, R., \& Debbarma, R. (2017). Performance evaluation of setback buildings with open ground storey on plain and sloping ground under earthquake loadings and mitigation of failure. International Journal of Advanced Structural Engineering, 9(2), 97. https://doi.org/10.1007/s40091-0170151-3

Hadzima-Nyarko, M., \& Kalman Sipos, T. (2017). Insights from existing earthquake loss assessment research in Croatia. Earthquakes and Structures, 13(4), 365-375. https://doi.org/10.12989/eas.2017.13.4.401

Hsiao, F. P., Oktavianus, Y., \& Ou, Y. C. (2015). A pushover seismic analysis method for asymmetric and tall buildings. Journal of the Chinese Institute of Engineers, 38(8), 9911001.https://doi.org/10.1080/02533839.2015.1056553

Işık, E., Özdemir, M., Karaşin, İ.B., Karaşin, A., (2019). Betonarme yapılarda kullanılan malzeme modellerinin karşılaştırılması. Bitlis Eren Üniversitesi Fen Bilimleri Dergisi, 8(3),

968-984. https://doi.org/10.17798/bitlisfen.520354

Işık, E., Özdemir, M., \& Karaşin, İ. B. (2018). Performance analysis of steel structures with A3 irregularities. International Journal of Steel Structures, 18(3), 1083-1094. https://doi.org/10.1007/s13296-018-0046-6

Işık, E., \& Özdemir, M. (2017). Performance based assessment of steel frame structures by different material models. International Journal of Steel Structures, 17(3), 1021-1031. https://doi.org/10.1007/s13296-017-9013-x 
Isik, E., Isik, M. F., \& Bulbul, M. A. (2017). Web based evaluation of earthquake damages for reinforced concrete buildings. Earthquakes and Structures, 13(4), 387-396. https://doi.org/10.12989/eas.2017.13.4.423

Işık, E., \& Kutanis M. (2015). Performance based assessment for existing residential buildings in Lake Van basin and seismicity of the region. Earthquakes and Structures, 9(4), 893-910. https://doi.org/10.12989/eas.2015.9.4.893

Iş1k, E. (2016). Consistency of the rapid assessment method for reinforced concrete buildings. Earthquakes and Structures, 11(5), https://doi.org/10.12989/eas.2016.11.5.873

873-885.

Işık, E. (2013). The evaluation of existing buildings Bitlis province using a visual screening method, SDU, Journal of Natural and Applied Sciences, 17(1), 173-178.

Karaşin, İ. B., Işı1k, E., Karaşin, A., \& Özdemir, M. (2017). Betonarme Yapılarda Tepe-Yamaç Etkisinin Yap1 Performansina Etkisi. International Conference on Multidisciplinary, Science, Engineering and Technology (IMESET'17), Bitlis, Türkiye.

Khadiranaikar, R. B., \& Masali, A. (2014). Seismic performance of buildings resting on sloping ground-a review. IOSR J Mech Civ Eng (IOSR-JMCE), 11(3), 12-19. https://doi.org/10.9790/1684-11331219

Kutanis, M., Boru, E. O., \& Işık, E. (2017). Alternative instrumentation schemes for the structural identification of the reinforced concrete field test structure by ambient vibration measurements. KSCE Journal of Civil Engineering, 21(5), 1793-1801. https://doi.org/10.1007/s12205-016-0758-0

Mander, J. B., Priestley, M. J. N., \& Park, R. (1998). Theoretical stress-strain model for confined concrete. Journal of Structural Engineerings, 114(8), 1804-1825. https://doi.org/10.1061/(ASCE)07339445(1988)114:8(1804)

Menegotto, M., \& Pinto, P. E. (1973). Method of analysis for cyclically loaded rc. plane frames including changes in geometry and non-elastic behavior of elements under combined normal force and bending. symposium on the resistance and ultimate deformability of structures acted on by well defined repeated loads, in International Association for Bridge and Structural Engineering, Zurich, Switzerland, 15-22.

Mohammad, Z., Baqi, A., \& Arif, M. (2017). Seismic response of RC framed buildings resting on hill slopes. Procedia Engineering, 173, 1792-1799. https://doi.org/10.1016/j.proeng.2016.12.221

Nikoo, M., Hadzima-Nyarko, M., Khademi, F., \& Mohasseb, S. (2017). Estimation of fundamental period of reinforced concrete shear wall buildings using self organization feature map. Structural Engineering and Mechanics, 63(2), 237-249. https://doi.org/10.12989/sem.2017.63.2.237

Ordu, E., \& Özkan, M. T. (2006). Three-dimensional finite element analysis of the seismic behavior of pile foundations. Itü Dergisi/d, 5(2), 27-34.

Ozcebe, G., Yucemen, M. S., Aydogan, V., \& Yakut, A. (2003). Preliminary seismic vulnerability assessment of existing reinforced concrete buildings in Turkey. In Seismic
Assessment and Rehabilitation of Existing Buildings (pp. 29-42). Springer, Dordrecht.

Öztürk, H., Demir, A., Dok, G., \& Güç, H. (2017). Betonarme kolonlarin etkin kesit rijitlikleri üzerine yönetmeliklerin yaklaşimlari. 4. Uluslararası Deprem Mühendisliği ve Sismoloji Konferans1 11-13 Ekim 2017, Eskişehir.

Pinto, P. E. (2005). The Eurocode 8-Part 3: the new European Code for the seismic assessment of existing structures.

Shakib, H., \& Pirizadeh, M. (2013). Probabilistic seismic performance assessment of setback buildings under bidirectional excitation. Journal of Structural Engineering, 140(2),

04013061.https://doi.org/10.1061/(ASCE)ST.1943541X.0000835

SeismoStruct v6.5 (2013). A computer program for static and dynamic nonlinear analysis of framed structures. Seismosoft.

Šipoš, T. K., \& Hadzima-Nyarko, M. (2017). Rapid seismic risk assessment. International Journal of Disaster Risk Reduction, 24, 348-360. https://doi.org/10.1016/j.ijdrr.2017.06.025

Sreerama, A. K., \& Ramancharla, P. K. (2013, October). Earthquake behavior of reinforced concrete framed buildings on hill slopes. In International Symposium on New Technologies for Urban Safety of Mega Cities in Asia (USMCA 2013).

Sucuoğlu, H., Yazgan, U., \& Yakut, A. (2007). A screening procedure for seismic risk assessment in urban building stocks. Earthquake Spectra, 23(2), 441-458. https://doi.org/10.1193/1.2720931

Tekeli, H., Dilmac, H., Demir, F., Gencoglu, M., \& Guler, K. (2017). Shear stress indicator to predict seismic performance of residential RC buildings. Computer and Concrete, 19(3), $283-$ 291.https://doi.org/10.12989/cac.2017.19.3.283

Tezcan, S. S., Bal, I. E., \& Gulay, F. G. (2011). P25 scoring method for the collapse vulnerability assessment of $\mathrm{R} / \mathrm{C}$ buildings. Journal of the Chinese Institute of Engineers, 34(6),

781.https://doi.org/10.1080/02533839.2011.591548

Ulutaş, H., Dilmac, H., Tekeli, H., \& Demir, F. (2019). Okul binalarında bulunması gereken perde duvar oranı üzerine bir çalışma. Mehmet Akif Ersoy Üniversitesi Fen Bilimleri Enstitüsü Dergisi, 10(1), 1-10. https://doi.org/10.29048/makufebed.500974

Yakut, A., Erberik, M. A., Ilki, A., Sucuoğlu, H., \& Akkar, S. (2014). Rapid seismic assessment procedures for the Turkish building stock. In Seismic Evaluation and Rehabilitation of Structures (pp. 15-35). Springer, Cham.

Yakut, A. (2004). Preliminary seismic performance assessment procedure for existing RC buildings. Engineering Structures, 26(10), 1447-1461. https://doi.org/10.1016/j.engstruct.2004.05.011

Xian, L., He, Z., \& Ou, X. (2016). Incorporation of collapse safety margin into direct earthquake loss estimate. Earthquakes and Structures, 10(2), 429-450. https://doi.org/10.12989/eas.2016.10.2.4 